\title{
Effect of Heat Treatment on the Electrochemical Properties of
}

\section{$\mathrm{La}_{0.6} \mathrm{Ce}_{0.2} \mathrm{Pr}_{0.05} \mathrm{Nd}_{0.15} \mathrm{Ni}_{3.55} \mathrm{Co}_{0.3} \mathrm{Mn}_{0.4} \mathrm{Al}_{0.3}\left(\mathrm{Cu}_{0.96} \mathrm{Be}_{0.04}\right)_{0.45}$ Hydrogen Storage}

\author{
Alloy \\ Xiaoqiang Han, Wenyuan $\mathrm{Wu}^{*}$, Xue Bian \\ School of Metallurgy, Northeastern University, Shenyang 110819, PR China \\ E-mail address:neuwuwenyuan@126.com \\ Tel./fax:+008602483680527
}

Keywords: $\mathrm{AB}{ }_{5}$-type hydrogen storage alloy;Microstructure characteristics; Hydrogen absorbing materials

Abstract.In this study, $\mathrm{La}_{0.6} \mathrm{Ce}_{0.2} \mathrm{Pr}_{0.05} \mathrm{Nd}_{0.15} \mathrm{Ni}_{3.55} \mathrm{Co}_{0.3} \mathrm{Mn}_{0.4} \mathrm{Al}_{0.3}\left(\mathrm{Cu}_{0.96} \mathrm{Be}_{0.04}\right)_{0.45}$ alloy was heat treated for $4 \mathrm{~h}$ in argon atmosphere at 923,1023 , and $1123 \mathrm{~K}$, respectively. The results of scanning electron microscopy indicated that surface morphology of the heat-treated alloys changed significantly. Before heat treatment, heterogeneous structure of the alloy was composed of white, black, and gray matrix phase, respectively. With the increase in heat treatment temperature, the composition of matrix phase became increasingly uniform. When heat treatment temperature was relatively low $(923 \mathrm{~K})$, the black phase with low melting point was distributed homogeneously. When the temperature increased to 1023 and $1273 \mathrm{~K}$, the gray phase increased. Discharge capacity of the four types of alloys with discharge cut-off voltage of $1.2 \mathrm{~V}$ was presented. In the first cycle, the capacity of three heat-treated alloys was less than $158.3 \mathrm{mAh} \mathrm{g} \mathrm{1,} \mathrm{which} \mathrm{was} \mathrm{similar} \mathrm{to} \mathrm{the}$ capacity of alloy without heat treatment. For alloy without heat treatment, maximum capacity reached up to $230.1 \mathrm{mAh} \mathrm{g}^{-1}$ in the third cycle, and the maximum capacity of alloy b reached up to $227.5 \mathrm{mAh} \mathrm{g}^{-1}$ in the third cycle. The maximum capacity of alloy c reached up to $228.2 \mathrm{mAh} \mathrm{g}^{-1}$ in the third cycle. The maximum capacity of alloy d reached up to $224.9 \mathrm{mAh} \mathrm{g}^{-1}$ in the third cycle.

\section{Introduction}

Energy and environment are the most important issues related to the sustainable development of human society. With the development and progress of human society, the consumption of energy and natural resources increased, resulting in the running out of fossil fuels and aggravation of environmental deterioration [1-5]. Although researchers have tried to reduce the environmental pollution from conventional sources of energy (coal, oil, etc.), extensive research efforts are still required to be devoted to the research, development, and application of sustainable and pollution-free non fossil energy, which is the technology development trend of energy region in the next century [6-9]. In the end of 1960s, Philips Laboratory in Netherland discovered that LiNi5 alloys have properties of reversible hydrogen absorbance and desorbance [10].

$\mathrm{La}_{0.6} \mathrm{Ce}_{0.2} \mathrm{Pr}_{0.05} \mathrm{Nd}_{0.15} \mathrm{Ni}_{3.55} \mathrm{Co}_{0.3} \mathrm{Mn}_{0.4} \mathrm{Al}_{0.3}\left(\mathrm{Cu}_{0.96} \mathrm{Be}_{0.04}\right)_{0.45}$ alloy with excellent electrochemical properties was investigated and effects of different heat treatment temperature on the properties of alloy were comprehensively studied. 


\section{Experimental}

\section{Preparation of hydrogen storage alloys}

Lanthanum (La) rich rare-earth compound with purity of more than $99 \%$ was blended in appropriate proportion with pure metals including $\mathrm{Ni}, \mathrm{Co}, \mathrm{Mn}, \mathrm{Al}$, and $\mathrm{Be}-\mathrm{Cu}$; and the mixture was smelted in medium frequency induction furnace. The hydrogen storage alloys were obtained from ingots through mechanical crushing.

\section{Preparation of alloy electrode}

Alloy powder (0.2 g, 200-300 mesh) was uniformly blended with Ni powder, and then the mixture was placed in die to prepare thin slice sample with diameter of $10 \mathrm{~mm}$ by cold pressing under $10 \mathrm{MPa}$.

$\mathrm{La}_{0.6} \mathrm{Ce}_{0.2} \mathrm{Pr}_{0.05} \mathrm{Nd}_{0.15} \mathrm{Ni}_{3.55} \mathrm{Co}_{0.3} \mathrm{Mn}_{0.4} \mathrm{Al}_{0.3}\left(\mathrm{Cu}_{0.96} \mathrm{Be}_{0.04}\right)_{0.45}$ alloy was vacuum sealed in quartz tube and heated in high temperature pipe furnace. Heat treatment under argon atmosphere was conducted at 923,1023 , and $1123 \mathrm{~K}$ with holding time of $4 \mathrm{~h}$, respectively. For the convenience of research, the heat treated alloys were numbered as listed in Table 1.

Table 1 Numbering of alloys before and after heat treatment

\begin{tabular}{cccc}
\hline $\mathrm{a}$ & $\mathrm{b}$ & $\mathrm{c}$ & $\mathrm{d}$ \\
\hline no heat treatment & $923 \mathrm{~K}(4 \mathrm{~h})$ & $1023 \mathrm{~K}(4 \mathrm{~h})$ & $1123 \mathrm{~K}(4 \mathrm{~h})$ \\
\hline
\end{tabular}

\section{Results and Discussions}

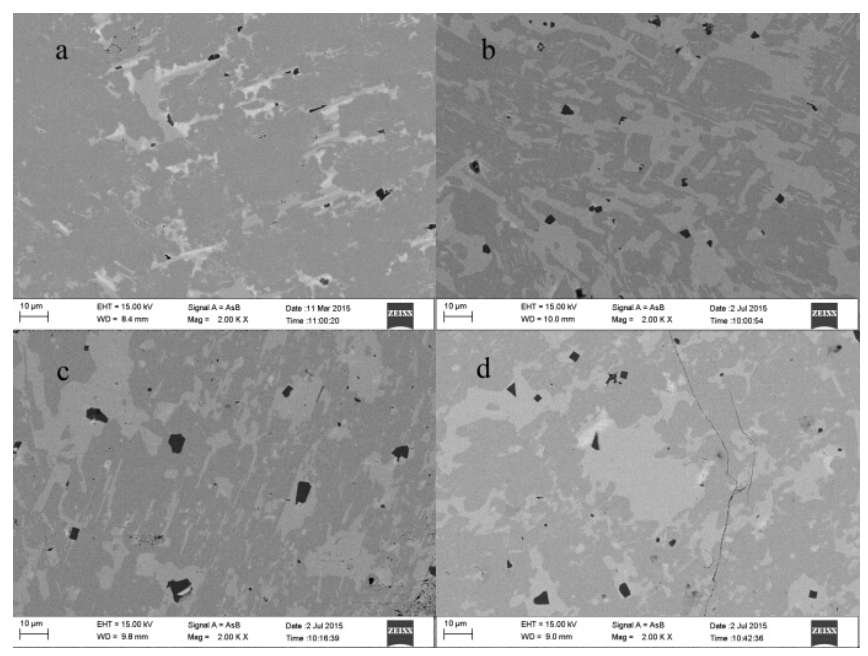

Fig. 1 SEM images of alloys before and after heat treatment

Fig. 1 exhibits the scanning electron microscopy (SEM) images of $\mathrm{La}_{0.6} \mathrm{Ce}_{0.2} \mathrm{Pr}_{0.05} \mathrm{Nd}_{0.15} \mathrm{Ni}_{3.55} \mathrm{Co}_{0.3} \mathrm{Mn}_{0.4} \mathrm{Al}_{0.3}\left(\mathrm{Cu}_{0.96} \mathrm{Be}_{0.04}\right)_{0.45}$ alloy before and after heat treatment, indicating significant changes in the surface morphology of alloys after heat treatment. Fig. 1(a) shows the alloy sample without heat treatment, exhibiting heterogeneous structure indicated by white, black, and gray matrix phase, respectively. With the increase in heat treatment temperature, the composition of matrix phase of alloys becomes increasingly uniform. When the heat treatment temperature is relatively low $(923 \mathrm{~K})$, the black phase with low melting point distributes homogeneously. However, with the increase in temperature to 1023 and $1273 \mathrm{~K}$, the gray phase increases. 


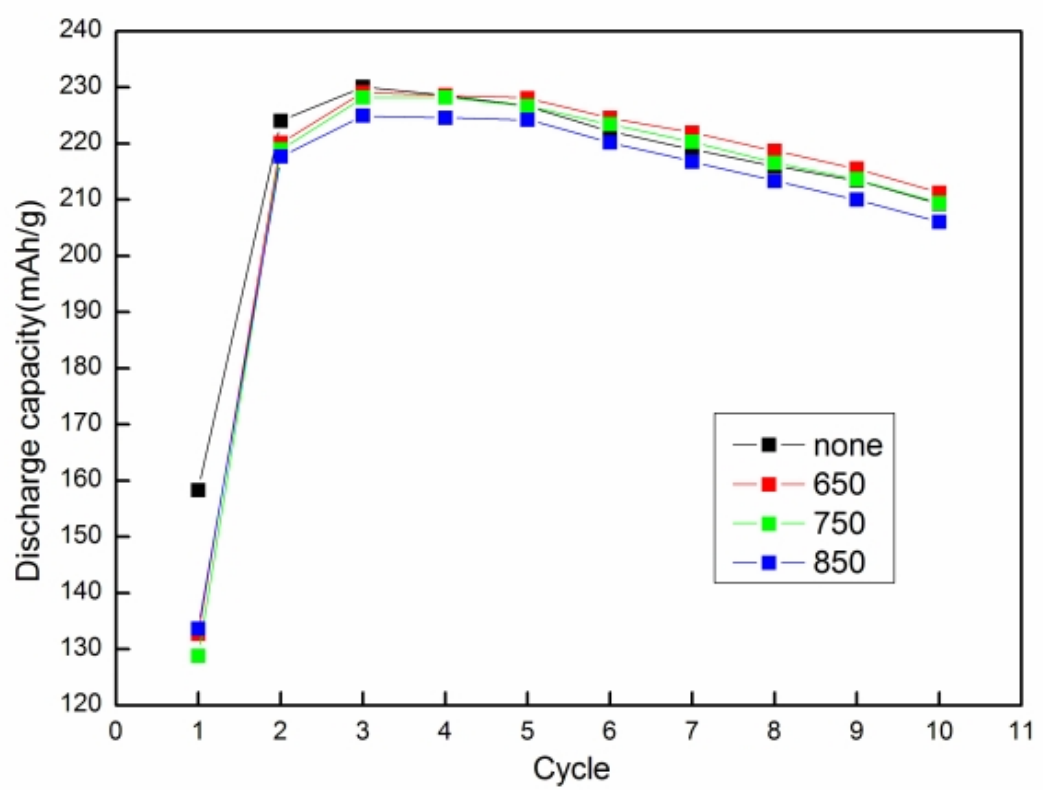

Fig.2 Discharge performance of alloys before and after heat treatment

The discharge capacities of these four types of alloys with discharge cut-off voltage of $1.2 \mathrm{~V}$ are presented in Fig. 2. In the first cycle, the capacity of three heat-treated alloys is less than $158.3 \mathrm{mAh}$ $\mathrm{g}^{-1}$, which was similar to the capacity of alloy without heat treatment. The maximum capacity of this alloy without heat treatment reaches up to $230.1 \mathrm{mAh} \mathrm{g}^{-1}$ in the third cycle, and the maximum capacity of alloy b reaches up to $227.5 \mathrm{mAh} \mathrm{g}^{-1}$ in the third cycle, thus the cycle performance of alloy $\mathrm{b}$ is improved. The maximum capacity of alloy c reaches up to $228.2 \mathrm{mAh} \mathrm{g}^{-1}$ in the third and fourth cycles. The maximum capacity of alloy $\mathrm{d}$ reaches up to $224.9 \mathrm{mAh} \mathrm{g}^{-1}$ in the third cycle. After heat treatment, component distribution in the alloy tended to be uniform and the crystal defects decreased. Although it exhibited positive significance to suppress the alloy pulverization, it exerted adverse effect on the activation properties of alloy. Thus, the implementation of heat treatment decreases the charging efficiency and reduces the discharge capacity of alloy.

\section{Conclusions}

The maximum capacity of the alloy without heat treatment reaches up to $230.1 \mathrm{mAh} \mathrm{g}^{-1}$ in the third cycle and the maximum capacity of alloy b reaches up to $227.5 \mathrm{mAh} \mathrm{g}^{-1}$ in the third cycle. The maximum capacity of alloy c reaches up to $228.2 \mathrm{mAh} \mathrm{g}^{-1}$ in the third cycle. The maximum capacity of alloy d reaches up to $224.9 \mathrm{mAh} \mathrm{g}^{-1}$ in the third cycle. The comparison indicates that the cycle performance of alloy $b$ is significantly improved.

\section{Reference}

[1] Int J Hydrogen Energy 31 (2006) 177-182

[2] J Power Sources 176 (2008) 547-554

[3] Int J Hydrogen Energy 2005;30:1091-1098.

[4] Int J Hydrogen Energy 2003;28:409-414.

[5] Journal of Power Sources 154 (2006) 456-460

[6] International Journal of Hydrogen Energy, 1984, 9(8): 649-668.

[7] Journal of Power Sources, 2001, 100(1-2): 117-124.

[8] Int J Hydrogen Energy 30 (2005) 1091-1098 
[9] Int J Hydrogen Energy 31 (2006) 678-682

[10] Journal of Less Commom Metals, 1991, 24(4): 1194-1201. 